\title{
The intercropping partner affects arbuscular mycorrhizal fungi and Fusarium oxysporum f. sp. lycopersici interactions in tomato
}

\author{
Karin Hage-Ahmed • Johannes Krammer • Siegrid Steinkellner
}

Received: 2 October 2012 /Accepted: 13 March 2013 /Published online: 3 April 2013

(C) The Author(s) 2013. This article is published with open access at Springerlink.com

\begin{abstract}
Arbuscular mycorrhizal fungi (AMF) and their bioprotective aspects are of great interest in the context of sustainable agriculture. Combining the benefits of AMF with the utilisation of plant species diversity shows great promise for the management of plant diseases in environmentally compatible agriculture. In the present study, AMF were tested against Fusarium oxysporum f. sp. lycopersici with tomato intercropped with either leek, cucumber, basil, fennel or tomato itself. Arbuscular mycorrhizal (AM) root colonisation of tomato was clearly affected by its intercropping partners. Tomato intercropped with leek showed even a $20 \%$ higher AM colonisation rate than tomato intercropped with tomato. Positive effects of AMF expressed as an increase of tomato biomass compared to the untreated control treatment could be observed in root as well as in shoot weights. A compensation of negative effects of $F$. oxysporum f. sp. lycopersici on tomato biomass by AMF was observed in the tomato/leek combination. The intercropping partners leek, cucumber, basil and tomato had no effect on $F$. oxysporum f. sp. lycopersici disease incidence or disease severity indicating no allelopathic suppression; however, tomato co-cultivated with tomato clearly showed a negative effect on one plant/pot with regard to biomass and disease severity of $F$. oxysporum f. sp. lycopersici. Nonetheless, bioprotective effects of AMF resulting in the decrease of $F$. oxysporum f. sp. lycopersici disease severity were evident in treatments with AMF and $F$. oxysporum f. sp. lycopersici co-inoculation. However, these bioprotective effects depended on the intercropping partner since these effects were only observed in the tomato/leek
\end{abstract}

\footnotetext{
K. Hage-Ahmed $(\bowtie) \cdot J$. Krammer $\cdot$ S. Steinkellner

Department of Crop Sciences, Division of Plant Protection, University of Natural Resources and Life Sciences, Vienna, Peter-Jordan-Strasse 82,

1190, Vienna, Austria

e-mail: karin.hageahmed@boku.ac.at
}

and tomato/basil combination and for the better developed plant of tomato/tomato. In conclusion, the effects of the intercropping partner on AMF colonisation of tomato are of great interest for crop plant communities and for the influences on each other. The outcome of the bioprotective effects of AMF resulting in the decrease on F. oxysporum $\mathrm{f}$. sp. lycopersici disease severity and/or compensation of plant biomass does not depend on the degree of AM colonisation but more on the intercropping partner.

Keywords AM fungi - Fusarium oxysporum $\mathrm{f}$. sp. lycopersici $\cdot$ Intercropping $\cdot$ Solanum lycopersicum . Biological control

\section{Introduction}

Arbuscular mycorrhizal fungi (AMF) are the most prevalent type of mycorrhizal fungi and form a mycorrhizal symbiosis with a wide range of vascular plants including many important crop species (Smith and Read 2008). Apart from improved plant nutrition, AMF are reputed to control a number of plant diseases, especially soil-borne diseases (AzcónAguilar et al. 2002; Whipps 2004; Singh et al. 2000; Xavier and Boyetchko 2004; St-Arnaud and Vujanovic 2007; Newsham et al. 1995). This is of high significance in the field of sustainable agriculture, where the input of fertilisers and chemical plant protectants is reduced or even absent. Furthermore, it is known that AMF have an impact on plant community structure and diversity by altering interor intraspecific competitive situations (Smith and Read 2008; van der Heijden et al. 2003; Schroeder-Moreno and Janos 2008). In return, however, arbuscular mycorrhizal (AM) fungal community structure can be influenced by the host plants (Smith and Read 2008; Bever 2002). These effects are well described for grassland communities; for 
crop species, only Schroeder-Moreno and Janos (2008) have reported similar effects. For the application of intercropping in combination with AMF, these feedback matters need to be kept in mind and need to be tested for each intercropping arrangement separately. Thus, further research is necessary for the application to crop species, especially with regard to intercropping arrangements with the aim of improved plant performance, which also implies lower infection rates caused by diseases. Plant species diversity could make a significant contribution to the reduction of plant diseases (Ratnadass et al. 2012). This would reduce the use of chemical pesticides and therefore reduce adverse effects on humans and the environment.

Fusarium oxysporum f. sp. lycopersici is a soil-borne fungus, which invades the plants through the roots and causes wilting in tomato which can result in severe yield losses. Apart from the environmental issues mentioned before, chemical control of soil-borne pathogens is difficult to impossible, thus, giving a further strong reason for alternative methods of disease control.

It has been shown previously that AMF reduced adverse effects of $F$. oxysporum f. sp. lycopersici in tomato when coinoculated with this pathogen (Dehne and Schönbeck 1979; Akköprü and Demir 2005). Apart from improved plant nutrition mechanisms like changes in root and vessel system, mycorrhizosphere effects and induced systemic resistance are involved in these effects (Akköprü and Demir 2005; Dehne and Schönbeck 1979; Whipps 2004). However, this bioprotective effect depends on the AM fungal identity (Sikes et al. 2009), making it crucial to choose the proper AMF isolates. Furthermore, it has been shown that allelopathic suppression by root exudates can occur in intercropping arrangements, like for tomato and Chinese chive against Pseudomonas solanacearum (Yu 1999) and for watermelon and rice against Fusarium oxysporum f. sp. niveum (Hao et al. 2010). A combination of the bioprotective effects of AMF and intercropping partners can be considered as a new potential strategy against soilborne pathogens and would be of high significance for sustainable agriculture.

In our work, we focused on tomato (Solanum lycopersicum L.) intercropped with leek (Allium porrum L.) and basil (Ocimum basilicum L.), commonly known as stimulating species, and fennel (Foeniculum vulgare (L.) Mill.) and cucumber (Cucumis sativus L.), known as species with adverse effects on tomato, in combination with a commercially available AMF inoculum. We hypothesised that the intercropping partners of tomato can have conducive, adverse or neutral effects on AMF and tomato wilt caused by $F$. oxysporum $\mathrm{f}$. $\mathrm{sp}$. lycopersici. The aim was to investigate (1) the AMF colonisation rate of tomato in intercropping settings, (2) the influence of AMF application in intercropping systems on $F$. oxysporum f. sp. lycopersici disease severity and (3) the effects of AMF and/or F. oxysporum f. sp. lycopersici in different intercropping systems on root and shoot weights of tomato.

\section{Material and methods}

Plant and fungal material

Tomato (S. lycopersicum L. cv. Kremser Perle), leek (A. porrum L. cv. Golem), fennel (F. vulgare (L.) Mill. cv. Fino), basil (O. basilicum L. cv. Genovese) and cucumber (C. sativus L. cv. Aztec F1) were used as crop plants. All seeds were surface-sterilised by soaking in $50 \%$ household bleach ('Dan Klorix', $3.8 \% \mathrm{NaOCl}$ ) for $10 \mathrm{~min}$ and rinsed afterwards three times with autoclaved distilled water. Seeds were transferred to pots filled with autoclaved perlite (Granuperl S 3-6, Knauf Perlite $\mathrm{GmbH}$, Vienna, Austria) and incubated in a growth chamber (York International) with a 16-h light (light intensity $296 \mu \mathrm{mol} \mathrm{m} \mathrm{s}^{-1} \mathrm{~s}^{-1}$ ) and 8 -h dark photoperiod at $24{ }^{\circ} \mathrm{C}$. The perlite was irrigated with tap water. Seeds of leek and fennel were pre-cultivated 6 weeks, and seeds of tomato and basil 3 weeks, before transplanting. Due to the rapid growth, cucumber seeds were used in the below described plant bioassay without pre-cultivation.

F. oxysporum f. sp. lycopersici (F. oxysporum f. sp. lycopersici007) was cultivated for 2 weeks at $24{ }^{\circ} \mathrm{C}$ in darkness on Czapek Dox Agar (Duchefa Biochemie, Haarlem, The Netherlands). For plant inoculation, a microconidial suspension was prepared by flooding the $F$. oxysporum f. sp. lycopersici colonies with sterile, distilled water and gently rubbing with a Drigalski spatula. Thereafter, the conidial suspension was filtered through three layers of cheese cloth (fleece filters, $20-150 \mu \mathrm{m}$ pore diameter, Laporte, Wels, Austria) and adjusted to a final concentration of $10^{5}$ microconidia $\mathrm{ml}^{-1}$.

For AMF plant inoculation, a commercially available inoculum (Symbivit ${ }^{\circledR}$, Zivojin Rilakovic, Guntramsdorf, Austria) was used. This inoculum contains at least 80,000 spores $1^{-1}$ and comprises six Glomus species (Glomus etunicatum, Glomus microagregatum, Glomus intraradices, Glomus claroidium, Glomus mosseae and Glomus geosporum).

\section{Plant bioassay}

Pre-cultivated plantlets of tomato, basil, leek and fennel and cucumber seeds were transferred to pots (volume $\left.1,183 \mathrm{~cm}^{-3}\right)$ filled with an autoclaved $\left(20 \mathrm{~min}\right.$ at $\left.121{ }^{\circ} \mathrm{C}\right)$ mixture of sand, soil and expanded clay $(1: 1: 1, v / v / v)$. The plants were cultivated as a dual culture system with the following plant combinations: tomato/tomato, tomato/basil, 
tomato/cucumber, tomato/fennel and tomato/leek. The experimental set-up included four different treatments for each dual culture: (1) F. oxysporum f. sp. lycopersici, (2) AMF, (3) F. oxysporum f. sp. lycopersici and AMF and (4) a control without $F$. oxysporum f. sp. lycopersici and without AMF. For each treatment three replicates comprising 6 pots each were used, giving 72 pots per plant combination and a total of 360 pots.

For the AMF treatment, $4 \mathrm{ml}$ of the AMF inoculum were added to the planting hole at the potting procedure. $F$. oxysporum f. sp. lycopersici was applied to the plant roots by dipping the roots for $5 \mathrm{~min}$ in a microconidial suspension $\left(10^{5}\right.$ microconidia $\left.\mathrm{ml}^{-1}\right)$ before plants were transferred to the pots. For the $\mathrm{AMF}+F$. oxysporum $\mathrm{f}$. sp. lycopersici treatment, both inocula were added as mentioned above.

The plants were grown in a random design in a greenhouse for 11 weeks and were irrigated according to their moisture requirements with a nutrient solution (Steinkellner et al. 2005).

After 11 weeks, the plants were gently removed from the substrate und washed thoroughly under tap water. Root and shoot fresh weights were determined. Plants of the tomato/tomato combination were separated into two groups per pot according to their root weights to assess intraspecific effects.

Disease incidence was calculated according to the following formula:

Disease incidence $=\frac{\text { Number of infected plants }}{\text { Total number of plants }} \times 100$

F. oxysporum f. sp. lycopersici disease severity was determined by measuring the amount of vessel discolouration of the stem in relation to the total stem length (length of infected stem $[\mathrm{cm}] /$ total length of stem $[\mathrm{cm}])$. Leaf symptoms were not evident at this plant stage and were therefore not considered for disease severity assessment. For confirmation of $F$. oxysporum f. sp. lycopersici infection, segments of 2-cm length starting upwards the shoot basis were dipped in $70 \%$ ethanol, flamed and put into Petri dishes containing potato dextrose agar amended with antibiotics to prevent bacterial growth according to Steinkellner et al. (2011). The determination of $F$. oxysporum f. sp. lycopersici was done according to Nelson et al. (1983) by visual and microscopic analyses.

Defined root segments of $1-\mathrm{cm}$ length, starting $2 \mathrm{~cm}$ down the shoot, were used for determining the degree of mycorrhization. The root segments were cleared by boiling for 4 min (tomato, cucumber, leek and fennel) and $5 \mathrm{~min}$ (basil), respectively, in $10 \% \mathrm{KOH}$ and afterwards rinsed three times with tap water. Roots were stained by boiling for 3 min in a $5 \%$ ink-vinegar solution (Vierheilig et al. 1998). The percentage of root colonisation was determined according to the method of McGonigle et al. (1990).
Statistical analyses

AM colonisation rate was rank-transformed and analysed by using one-way ANOVA and Bonferroni's test. Data of disease severity were analysed by Kruskal-Wallis and MannWhitney $U$ test. Since neither root nor shoot weights met the homogeneity assumption of variance, even after transformation, a two-way ANOVA could not be applied. Therefore, data were analysed by one-way ANOVA (cross-checked with Welch's ANOVA) and Tamhane's test. Correlation analyses were based on Spearman's rho. All statistical analyses were performed using PASW Statistics 18.

\section{Results}

\section{AM colonisation}

The intercropping partner significantly influenced the AM colonisation levels of tomato plants $\left(F_{8,151}=18.761\right.$, $P<0.0001$ ) (Fig. 1). Tomato plants intercropped with leek showed a $20 \%$ higher colonisation level of the roots than tomato co-cultivated with tomato, whereas, tomato intercropped with fennel showed a $13 \%$ lower AM colonisation level. Tomato intercropped with cucumber and basil, respectively, did not reveal any differences in the AM colonisation level compared to the tomato/tomato (TT) combination. Within the TT combination, tomato plants grown in one pot did not show any differences in their AM colonisation levels. Tomato and basil plants in the tomato/basil (TB)

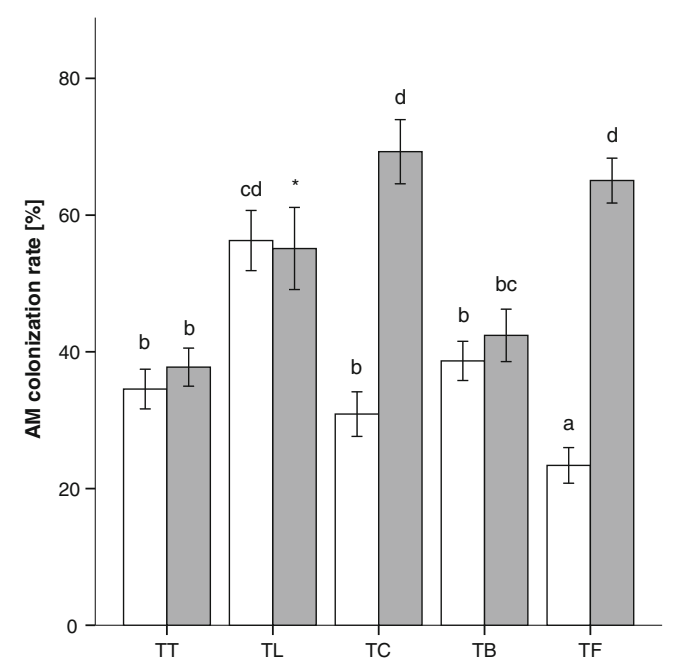

Fig. 1 AM colonisation rate (\%) of different plant species in different intercropping combinations (mean \pm standard error). $T=$ tomato, $L=$ leek, $C$ = cucumber, $B=$ basil, $F=$ fennel; empty bars represent the tomato plants and grey bars the corresponding intercropping partner. Plants were only inoculated with AMF. Different letters indicate significant difference according to ANOVA and Bonferroni's test $(P<$ $0.05)$ * excluded from statistical analysis 
combination did not show any significant differences in their AM colonisation rates, whereas for tomato and cucumber in the tomato/cucumber (TC) combination, cucumber had a 2.3-fold higher AM colonisation level than tomato. Furthermore, fennel in the tomato/fennel (TF) combination had a 2.7-fold higher colonisation level than the tomato plants. The AM colonisation level of leek $(55.11 \pm 6.0)$ in the tomato/leek (TL) combination was not considered for ANOVA due to its high variance caused by the small root system of the leek plants. However, AM colonisation level was similar to the one of tomato in the TL combination. AM colonisation levels are only shown for the AMF treatment since $F$. oxysporum f. sp. lycopersici did not show an influence on the AM colonisation levels compared to the AMF treatment alone. Plants of the control and $F$. oxysporum $\mathrm{f}$. sp. lycopersici treatment were also checked for AM colonisation but did not show any presence of AMF.

Assessment of F. oxysporum f. sp. lycopersici disease incidence and disease severity

F. oxysporum f. sp. lycopersici disease incidence and disease severity are presented in Table 1. For the TT combination, means of all plants from pots are given. Also, tomato plants of one pot were separated according to their root weights (see also Table 2) to see intraspecific effects and presented as Tomato_1 (T_1) and Tomato_2 (T_2). When considering all plants, the disease incidence of TT was 80.6 and $52.9 \%$ in the F. oxysporum f. sp. lycopersici and $\mathrm{AMF}+F$. oxysporum f. sp. lycopersici treatments, respectively, so that disease incidence was $35 \%$ less in the AMF $+F$. oxysporum f. sp. lycopersici treatment than in the F. oxysporum f. sp. lycopersici treatment.
In the other dual cultures, $\mathrm{AMF}+F$. oxysporum f. sp. lycopersici also showed lower disease incidences than the F. oxysporum f. sp. lycopersici treatment alone. The plant combinations had no impact on $F$. oxysporum f. sp. lycopersici disease incidence. With regards to root weights of the tomato plants of one pot, disease incidence in the TT combination of $\mathrm{T}_{-} 1$ was reduced in the $\mathrm{AMF}+F$. oxysporum $\mathrm{f}$. sp. lycopersici treatment (37.5\%) and, consequently, showed almost $50 \%$ less disease incidence than in the F. oxysporum f. sp. lycopersici treatment (72.2\%).

Disease severity within the $F$. oxysporum f. sp. lycopersici treatment ranged between 14.0 and $16.2 \%$ and between 4.4 and $14.32 \%$ within the $\mathrm{AMF}+F$. oxysporum f. sp. lycopersici treatment. The plant combinations had neither in the F. oxysporum f. sp. lycopersici $\left(\chi_{(4)}^{2}=0.412, P=0.981\right)$ nor in the AMF $+F$. oxysporum $\mathrm{f}$. sp. lycopersici treatment $\left(\chi_{(4)}^{2}=\right.$ $0.195, P=0.700$ ) a significant influence on $F$. oxysporum $\mathrm{f}$. sp. lycopersici disease severity. Within the TL and TB combinations, $\mathrm{AMF}+F$. oxysporum f. sp. lycopersici reduced disease severity significantly by $70 \%(P<0.05)$ and $63 \%(P<0.05)$, respectively. In the other plant combinations, the AMF + $F$. oxysporum f. sp. lycopersici treatment also tended to show lower disease severity. Within $\mathrm{T}_{-} 1, F$. oxysporum $\mathrm{f}$. sp. lycopersici showed higher disease severity than AMF + F. oxysporum f. sp. lycopersici $(P<0.05)$. Within T_2, disease severity was similar between $F$. oxysporum f. sp. lycopersici and $\mathrm{AMF}+F$. oxysporum $\mathrm{f}$. sp. lycopersici $(P=0.703)$. Within the $F$. oxysporum $\mathrm{f}$. sp. lycopersici $(P<0.05)$ as well as in the $\mathrm{AMF}+F$. oxysporum $\mathrm{f}$. sp. lycopersici $(P<0.05)$ column, T_1 had significantly lower disease severity than T_2. There was no significant correlation between disease severity and AM colonisation rate $\left(P=0.778, R^{2}=0.0008\right)$.

Table 1 F. oxysporum f. sp. lycopersici disease incidence and disease severity (\%) in the different plant combinations (mean \pm S.E.)

\begin{tabular}{|c|c|c|c|c|}
\hline \multirow[t]{2}{*}{ Dual culture } & \multicolumn{2}{|c|}{ Disease incidence $(\%)$} & \multicolumn{2}{|c|}{ Disease severity (\%) } \\
\hline & $\begin{array}{l}\text { F. oxysporum } \\
\text { f. sp. lycopersici }\end{array}$ & $\begin{array}{l}\mathrm{AMF}+F \text {. oxysporum } \\
\text { f. sp. lycopersici }\end{array}$ & $\begin{array}{l}\text { F. oxysporum } \\
\text { f. sp. lycopersici }\end{array}$ & $\begin{array}{l}\text { AMF }+F \text {. oxysporum } \\
\text { f. sp. lycopersici }\end{array}$ \\
\hline Tomato/tomato ${ }^{a}$ & 80.6 & 52.9 & $16.2 \pm 2.1 \mathrm{~A} \mathrm{a}$ & $14.32 \pm 3.8 \mathrm{~A} \mathrm{a}$ \\
\hline Tomato/leek & 66.7 & 44.4 & $14.3 \pm 3.4 \mathrm{~B} \mathrm{a}$ & $4.4 \pm 1.5 \mathrm{~A} \mathrm{a}$ \\
\hline Tomato/cucumber & 81.3 & 55.6 & $15.8 \pm 3.9 \mathrm{~A} \mathrm{a}$ & $7.0 \pm 2.2 \mathrm{~A} \mathrm{a}$ \\
\hline Tomato/basil & 72.2 & 55.6 & $14.2 \pm 2.9 \mathrm{~B} \mathrm{a}$ & $5.3 \pm 1.7 \mathrm{~A} \mathrm{a}$ \\
\hline Tomato/fennel & 66.7 & 55.6 & $14.0 \pm 2.8 \mathrm{~A} \mathrm{a}$ & $6.9 \pm 2.0 \mathrm{~A} \mathrm{a}$ \\
\hline Tomato/tomato $\left(\mathrm{T}_{-} 1\right)^{\mathrm{b}}$ & 72.2 & 37.5 & $11.4 \pm 2.4 \mathrm{~B} \mathrm{x}$ & $3.8 \pm 1.3 \mathrm{~A} \mathrm{x}$ \\
\hline Tomato/tomato $\left(\mathrm{T} \_2\right)^{\mathrm{c}}$ & 88.8 & 66.7 & $21.0 \pm 3.0 \mathrm{Ay}$ & $23.7 \pm 6.4 \mathrm{Ay}$ \\
\hline
\end{tabular}

Different letters indicate significant differences, small letters among columns (Kruskal-Wallis test, $P<0.05$ ), capital letters among rows $($ MannWhitney $U$ test, $P<0.05$ ).

${ }^{\text {a }}$ Data were calculated for both plants/pot

${ }^{b}$ Data were calculated for the stronger tomato plant/pot according to the root weight

${ }^{\mathrm{c}}$ Data were calculated for the weaker tomato plant/pot according to the root weight 
Table 2 Root weights (in grams) of tomato plants grown in a dual culture system (mean \pm S.E.)

\begin{tabular}{|c|c|c|c|c|c|}
\hline \multirow[t]{2}{*}{ Dual culture } & \multicolumn{4}{|l|}{ Treatment } & \\
\hline & Control & $\begin{array}{l}\text { F. oxysporum } \\
\text { f. sp. lycopersici }\end{array}$ & $\mathrm{AMF}$ & $\begin{array}{l}\mathrm{AMF}+F . \text { oxysporum } \\
\text { f. sp. lycopersici }\end{array}$ & \\
\hline Tomato/tomato (T_1) ${ }^{\mathrm{a}}$ & $6.36 \pm 0.44(\mathrm{~A}) \mathrm{cd}$ & $5.76 \pm 0.41(\mathrm{~A}) \mathrm{c}$ & $7.11 \pm 0.48$ (B) bc & $4.90 \pm 0.36(\mathrm{~A}) \mathrm{bc}$ & $\begin{array}{l}F_{(3,66)}=4.549 \\
P<0.01\end{array}$ \\
\hline Tomato/tomato (T_2) ${ }^{\mathrm{b}}$ & $3.71 \pm 0.24(\mathrm{~B}) \mathrm{a}$ & $2.42 \pm 0.26(\mathrm{~A}) \mathrm{a}$ & $4.42 \pm 0.39(\mathrm{~B}) \mathrm{a}$ & $2.45 \pm 0.35(\mathrm{~A}) \mathrm{a}$ & $\begin{array}{l}F_{(3,67)}=9.713 \\
P<0.0001\end{array}$ \\
\hline Tomato/leek & $7.03 \pm 0.22(\mathrm{~A}) \mathrm{d}$ & $5.87 \pm 0.46(\mathrm{~A}) \mathrm{c}$ & $8.47 \pm 0.46$ (B) d & $6.06 \pm 0.39(\mathrm{AB}) \mathrm{c}$ & $\begin{array}{l}F_{(3,67)}=8.947 \\
P<0.0001\end{array}$ \\
\hline Tomato/ cucumber & $5.14 \pm 0.46$ (B) abc & $2.70 \pm 0.35(\mathrm{~A}) \mathrm{ab}$ & $5.42 \pm 0.54(\mathrm{~B}) \mathrm{ab}$ & $3.55 \pm 0.47(\mathrm{AB}) \mathrm{ab}$ & $\begin{array}{l}F_{(3,66)}=7.095 \\
P<0.0001\end{array}$ \\
\hline Tomato/basil & $7.15 \pm 0.36(B) d$ & $5.57 \pm 0.40(\mathrm{~A}) \mathrm{c}$ & $8.90 \pm 0.27$ (B) d & $6.79 \pm 0.73(\mathrm{AB}) \mathrm{c}$ & $\begin{array}{l}F_{(3,68)}=8.424 \\
P<0.0001\end{array}$ \\
\hline \multirow[t]{2}{*}{ Tomato/fennel } & $4.80 \pm 0.15(\mathrm{~A}) \mathrm{b}$ & $4.32 \pm 0.41(\mathrm{~A}) \mathrm{bc}$ & $6.23 \pm 0.26(\mathrm{~B}) \mathrm{b}$ & $5.42 \pm 0.22(\mathrm{AB}) \mathrm{c}$ & $\begin{array}{l}F_{(3,68)}=9.006 \\
P<0.0001\end{array}$ \\
\hline & $\begin{array}{l}F_{(5,101)}=16.695 \\
P<0.0001\end{array}$ & $\begin{array}{l}F_{(5,100)}=15.735 \\
P<0.0001\end{array}$ & $\begin{array}{l}F_{(5,101)}=17.336 \\
P<0.0001\end{array}$ & $\begin{array}{l}F_{(5,101)}=12.823 \\
P<0.0001\end{array}$ & \\
\hline
\end{tabular}

Different letters indicate significant differences; capital letters among rows, i.e. plant combinations and letters among columns, i.e. treatments (ANOVA and Tamhane's test $P<0.05$ )

${ }^{a}$ Data were calculated for the stronger tomato plant/pot according to the root weight

${ }^{\mathrm{b}}$ Data were calculated for the weaker tomato plant/pot according to the root weight

Effect of intercropping, AMF and F. oxysporum f. sp. lycopersici on tomato growth

Plant growth of tomato in the different plant combinations and treatments was assessed by root and shoot weights.

\section{Root effects}

Root weights for the treatments with $F$. oxysporum f. sp. lycopersici and/or AMF application within the different plant combinations are shown in Table 2. The factor 'intercropping partner' had in each treatment a significant effect on tomato root weights (for $p$ values, see Table 2). Root weights of T_1 and T_2 of the TT combination in the control treatment differed significantly, indicating an intraspecific effect of tomato plants. Plants of T_2 had almost $50 \%$ less weight than the ones from $\mathrm{T}_{-} 1$. TL and TB showed the highest tomato root weights, whilst TC and TF ranged between the lowest and the highest root weights. These trends were also seen in the $F$. oxysporum f. sp. lycopersici, $\mathrm{AMF}$ and $\mathrm{AMF}+F$. oxysporum f. sp. lycopersici treatments.

The factor 'treatment' had in each dual culture a significant influence on root weights (for $p$ values, see Table 2). For T_2 within the TT treatment, $F$. oxysporum f. sp. lycopersici as well as AMF $+F$. oxysporum f. sp. lycopersici significantly reduced the root weight compared to the control treatment. For T 1, this effect could not be observed. A significant reduction of the root weights in the $F$. oxysporum f. sp. lycopersici treatment compared to the control could also be observed in TC. The AMF treatment over all plant combinations showed similar root weights as the corresponding control treatments, apart from TL, TF and $\mathrm{T}_{-} 1$ of TT which showed an increase in root weights. AMF $+F$. oxysporum f. sp. lycopersici over all plant combinations did not show a change in root weights compared to the $F$. oxysporum f. sp. lycopersici or control treatment, apart from $\mathrm{AMF}+F$. oxysporum f. sp. lycopersici of $\mathrm{T} \_2$, where the root weight was reduced compared to the control. There was no significant correlation between root weight and AM colonisation rate $\left(P=0.113, R^{2}=0.012\right)$; however, root weight was negatively correlated with disease severity $(P<$ $\left.0.0001, R^{2}=0.233\right)$.

\section{Shoot effects}

Shoot weights of tomato plants from the different plant combinations are shown in Table 3. The factor 'intercropping partner' had a significant effect on tomato shoot weights in each treatment (for $p$ values see Table 3). Within the control treatment, T 2 of the TT combination showed around $40 \%$ less shoot weight than $\mathrm{T} 1$. The highest shoot weights were reached by tomato plants of the TB and TL combinations (increases up to 320 and $180 \%$, compared to T_2 and T_1, respectively). The shoot weights of the tomato plants of the TC and TF combinations ranged between 11.49 and 13 . 
$06 \mathrm{~g}$ and were therefore higher than the shoot weights of T_2 (6.23 g).

The factor 'treatment' had a significant influence on shoot weights in each dual culture (for $p$ values, see Table 3). In the TT combination, shoot weights of T_1 showed a significant increase of $70-80 \%$ in the AMF and $\mathrm{AMF}+F$. oxysporum $\mathrm{f}$. sp. lycopersici treatments, compared to the control and $F$. oxysporum $\mathrm{f}$. sp. lycopersici treatment. A similar picture can be seen within the TL and TF combinations, where the shoot weights increased up to $200-230 \%$ and 170-210\%, respectively, compared to the control and $F$. oxysporum f. sp. lycopersici treatment. In T_2 of the TT combination, the $F$. oxysporum $\mathrm{f}$. sp. lycopersici treatment reduced the shoot weights of the plants compared to the control and the AMF treatment. On the other hand, AMF as well as $\mathrm{AMF}+F$. oxysporum $\mathrm{f}$. sp. lycopersici increased the shoot weights as compared to the control and the $F$. oxysporum f. sp. lycopersici treatment in T_1 of the TT combination, the TL and the TF combinations. In T 2 of the TT combination, the TC and TB combinations, AMF increased the shoot weights compared to the $F$. oxysporum $\mathrm{f}$. sp. lycopersici treatment, whereas the $\mathrm{AMF}+F$. oxysporum $\mathrm{f}$. sp. lycopersici treatment did not change the shoot weights compared to the $F$. oxysporum f. sp. lycopersici treatment. There was a low positive correlation between shoot weight and AM colonisation levels $\left(P<0.01, R^{2}=0.040\right)$; however, shoot weight was negatively correlated with disease severity $\left(P<0.0001, R^{2}=0.200\right)$

\section{Discussion}

Mycorrhizal symbiosis with its aspects of biofertilization and bioprotection is of special interest in the context of sustainable agriculture. The present work assessed the impact of AMF in an intercropping system with the main focus on the performance of tomato (cv. Kremser Perle). As far as AM root colonisation of tomato is concerned, this was clearly affected by the intercropping plant partners. Tomato intercropped with leek showed a $20 \%$ higher colonisation level than tomato intercropped with tomato. Fennel on the other hand decreased the colonisation level of tomato by $13 \%$. Leek had a similar colonisation level $(55.11 \%)$ as its intercropping partner tomato. However, the AM colonisation values of leek had a very high standard deviation, probably due to the rather small root system leading to a small amount of material for AM colonisation assessment. The well-established AM symbiosis in leek stimulated the colonisation of tomato, an effect that is concordant with data reported by Cavagnaro et al. (2004), and additionally, is in line with the frequent use of leek as nurse plants in experimental set-ups (Smith and Read 2008). However, a high AM colonisation level of the intercropping partner does not necessarily imply an increase in colonisation of the other one, as can be seen in the results with cucumber and fennel.

The small size of the rooting system of leek and as a consequence a faster colonisation of the root system and

Table 3 Shoot weights (in grams) of tomato plants grown in a dual culture system (mean \pm S.E.)

\begin{tabular}{|c|c|c|c|c|c|}
\hline \multirow[t]{2}{*}{ Dual culture } & \multicolumn{4}{|l|}{ Treatment } & \\
\hline & Control & $\begin{array}{l}\text { F. oxysporum } \\
\text { f. sp. lycopersici }\end{array}$ & $\mathrm{AMF}$ & $\begin{array}{l}\mathrm{AMF}+F . \text { oxysporum } \\
\text { f. sp. lycopersici }\end{array}$ & \\
\hline Tomato/tomato $\left(\mathrm{T}_{-} 1\right)^{\mathrm{a}}$ & $10.79 \pm 0.83(\mathrm{~A}) \mathrm{b}$ & $10.11 \pm 0.70(\mathrm{~A}) \mathrm{bc}$ & $19.17 \pm 1.32(\mathrm{~B}) \mathrm{b}$ & $16.66 \pm 1.60(\mathrm{~B}) \mathrm{bc}$ & $\begin{array}{l}F_{(3,66)}=15.279 \\
P<0.0001\end{array}$ \\
\hline Tomato/tomato $\left(\mathrm{T} \_2\right)^{\mathrm{b}}$ & $6.23 \pm 0.53(\mathrm{~B}) \mathrm{a}$ & $4.15 \pm 0.28(\mathrm{~A}) \mathrm{a}$ & $10.22 \pm 1.08(\mathrm{C}) \mathrm{a}$ & $8.21 \pm 1.49(\mathrm{ABC}) \mathrm{a}$ & $\begin{array}{l}F_{(3,67)}=7.398 \\
P<0.0001\end{array}$ \\
\hline Tomato/leek & $18.67 \pm 0.72(\mathrm{~B}) \mathrm{c}$ & $14.10 \pm 1.20(\mathrm{~A}) \mathrm{cd}$ & $31.73 \pm 1.31(\mathrm{C}) \mathrm{d}$ & $28.71 \pm 2.32(\mathrm{C}) \mathrm{d}$ & $\begin{array}{l}F_{(3,67)}=30.005 \\
P<0.0001\end{array}$ \\
\hline Tomato/ cucumber & $11.49 \pm 0.66(\mathrm{~A}) \mathrm{b}$ & $7.95 \pm 1.22(\mathrm{~A}) \mathrm{ab}$ & $16.72 \pm 1.50(\mathrm{~B}) \mathrm{b}$ & $12.62 \pm 1.94(\mathrm{AB}) \mathrm{ab}$ & $\begin{array}{l}F_{(3,66)}=6.293 \\
P=0.001\end{array}$ \\
\hline Tomato/basil & $19.05 \pm 0.86(\mathrm{~A}) \mathrm{c}$ & $16.85 \pm 1.21(\mathrm{~A}) \mathrm{d}$ & $27.94 \pm 1.96$ (B) d & $21.77 \pm 2.11(\mathrm{AB}) \mathrm{cd}$ & $\begin{array}{l}F_{(3,68)}=8.789 \\
P<0.0001\end{array}$ \\
\hline \multirow[t]{2}{*}{ Tomato/fennel } & $13.06 \pm 0.58(\mathrm{~A}) \mathrm{b}$ & $11.15 \pm 0.80(\mathrm{~A}) \mathrm{bc}$ & $23.78 \pm 1.67$ (B) bc & $21.96 \pm 1.77(\mathrm{~B}) \mathrm{c}$ & $\begin{array}{l}F_{(3,66)}=23.058 \\
P<0.0001\end{array}$ \\
\hline & $\begin{array}{l}F_{(5,101)}=48.299 \\
P<0.0001\end{array}$ & $\begin{array}{l}F_{(5,100)}=22.359 \\
P<0.0001\end{array}$ & $\begin{array}{l}F_{(5,101)}=26.616 \\
P<0.0001\end{array}$ & $\begin{array}{l}F_{(5,100)}=15.169 \\
P<0.0001\end{array}$ & \\
\hline
\end{tabular}

Different letters indicate significant differences; capital letters among rows, i.e. plant combinations and letters among columns, i.e. treatments (ANOVA and Tamhane's test $P<0.05$ )

${ }^{a}$ Data were calculated for the stronger tomato plant/pot according to the root weight

${ }^{\mathrm{b}}$ Data were calculated for the weaker tomato plant/pot according to the root weight 
development of hyphal networks, which are apart from spores and root fragments, of high significance in AM root colonisation (Smith and Read 2008) might be the reason for the increased colonisation rates compared to intercrops like tomato, cucumber, basil and fennel. Furthermore, putative colonisation preferences could have more impact when larger root systems are available. The colonisation preference observed for cucumber of the AMF used in the present work is consistent with the findings of Kubota and Hyakumachi (2004), who tested cucumber as well as tomato in soils of different vegetation sites with native AMF species and found a clear colonisation preference of AMF for cucumber; however this is not in an intercropping setting with different AMF. The importance of intercropping or individual settings can be seen in the work of Cavagnaro et al. (2004), who reported that mycorrhizal responsiveness of the tomato variety $76 \mathrm{R}$ to Glomus coronatum depended on the presence or absence of a mycorrhiza-defective tomato mutant derived from cv. 76R (i.e. a setting with interspecific competition). It therefore appears probable that the outcome of an AMFplant interaction in intercropping settings cannot be predicted from individual settings. The significance of the intercropping partner for AM colonisation levels is clearly shown in the present study on tomato.

The investigation of the influence of AMF and/or $F$. oxysporum f. sp. lycopersici on growth of intercropped tomato showed that the intercropping partners of tomato impacted on root and shoot weight. Most striking was the reduction of 50 and $40 \%$, respectively, in the root and shoot weights of one tomato plant/pot in the TT control treatment compared to the other tomato plant. AMF did not change the effects of the intercropping partner on these growth parameters compared to the control treatment. Root and shoot weight increases were AMF-dependent and not intercropping partner-dependent. Schroeder-Moreno and Janos (2008) found that AMF had negative effects on the root as well as on the shoot weights of chilli, maize and zucchini grown in intraspecific density settings. Negative effects on tomato root or shoot weights due to AMF could not be observed in the present work. However, lowest density here was two and not three plants, as in the work of Schroeder-Moreno and Janos (2008). With regards to interspecific competition, van der Heijden et al. (2003) clearly showed that the AMF species can influence the outcome of a competitive situation between plants. Working with Brachypodium pinnatum and Prunella vulgaris, these authors observed that the way in which the two plants coexisted depended on the Glomus isolate inoculated. In the present work, six different Glomus species were inoculated together; it would be interesting to test different AMF inocula separately in the same intercropping setting to find out more about such dynamics.

When assessing the influence of AMF inoculation in intercropping systems on $F$. oxysporum f. sp. lycopersici disease severity in tomato, a bioprotective effect was observed. This bioprotective effect resulted in a reduced disease severity in $A M$ plants of the $T-1, T L$ and $T B$ treatments. Looking on $\mathrm{T} 1, \mathrm{TL}$ and $\mathrm{TF}, \mathrm{AMF}+F$. oxysporum f. sp. lycopersici-treated plants produced more shoot biomass compared to the $F$. oxysporum f. sp. lycopersici-treated plants. Thus, mycorrhization enhances the tolerance of the tomato plants to the pathogen. Positive effects of AMF, expressed as an increase in biomass compared to the control treatment, could be observed for root as well as shoot weights. For roots, these effects could be observed for the AMF treatment in T_1 of TL and TF, whilst for shoots, the positive effects on biomass could be observed for $\mathrm{AMF}$ as well as $\mathrm{AMF}+F$. oxysporum $\mathrm{f}$. sp. lycopersici treatments in T_ 1 of TT, TL and TF combinations. $F$. oxysporum f. sp. lycopersici clearly reduced and AMF clearly increased shoot biomass for $\mathrm{T} 22$ and TL. Consequently, the positive effects of AMF co-inoculation with $F$. oxysporum f. sp. lycopersici on plant biomass are shown in shoot weights and not in reduced disease incidence. Compensation by AMF for the negative effects of $F$. oxysporum f. sp. lycopersici on plant biomass could particularly be reached with leek as intercropping partner. Thus, a well-chosen intercropping partner like leek and basil can allow expression of a bioprotective effect of AMF, even when the symbiosis is not established before pathogen inoculation. A different experimental set-up, like in Dehne and Schönbeck (1979), where AMF were applied 6 and 9 weeks, respectively, before $F$. oxysporum f. sp. lycopersici inoculation might have led to more positive effects. However, a simultaneous inoculation in an intercropping setting appears to be more comparable to natural conditions where concurrent activity of AMF and $F$. oxysporum f. sp. lycopersici will not be uncommon.

When tomato was intercropped with tomato, one intercropping partner turned to be the 'stronger' and the other the 'weaker' one, which also clearly affected the disease incidence and disease severity. Thus, keeping tomato in a competitive situation with itself has adverse effects on the biomass of one of the intercropping partners. The 'weaker' partner also showed significantly higher $F$. oxysporum f. sp. lycopersici disease severity and no positive effects of AMF inoculation. Therefore, we conclude that the positive effects of AMF on disease severity are limited in competitive situations, and that the intercropping partner affects the positive effects of AMF on tomato plants with regard to $F$. oxysporum f. sp. lycopersici disease severity. Results indicate that leek and basil are candidates for further intercropping setups, where further questions like fruit yield and fruit quality of tomatoes should be assessed and also the impact of pre-colonisation by AMF of intercropping partners could be investigated. 
To summarise, tomato intercropped with different species had no effect on $F$. oxysporum f. sp. lycopersici disease incidence or disease severity indicating no allelopathic suppression. However, tomato intercropped with tomato clearly showed negative effects on one plant/pot with regard to biomass and disease severity of $F$. oxysporum f. sp. lycopersici. Furthermore, crucial effects of the intercropping partner on AMF colonisation of tomato were found, which is of great interest in crop plant communities and the influences on each other. However, the outcome of the AMF effects on $F$. oxysporum f. sp. lycopersici disease severity and/or plant biomass did not depend on the degree of AM colonisation but more on the intercropping partner.

Acknowledgments This work was founded by the Austrian Science Fund (FWF, P20923-B17). The authors are thankful to the anonymous reviewers for the valuable comments on this paper.

Open Access This article is distributed under the terms of the Creative Commons Attribution License which permits any use, distribution, and reproduction in any medium, provided the original author(s) and the source are credited.

\section{References}

Akköprü A, Demir S (2005) Biological control of Fusarium wilt in tomato caused by Fusarium oxysporum f.sp. lycopersici by AMF Glomus intraradices and some rhizobacteria. J Phytopathol 153:544-550

Azcón-Aguilar C, Jaizme-Vega MC, Calvet C (2002) The contribution of arbuscular mycorrhizal fungi to the control of soil-borne plant pathogens. In: Gianinazzi S, Schüepp H, Barea JM, Haselwandter K (eds) Mycorrhizal technology in agriculture. Birkhäuser Verlag, Switzerland, pp 187-197

Bever J (2002) Host-specificity of AM fungal population growth rates can generate feedback on plant growth. Plant Soil 244:281-290

Cavagnaro TR, Smith FA, Hay G, Carne-Cavagnaro VL, Smith SE (2004) Inoculum type does not affect overall resistance of an arbuscular mycorrhiza-defective tomato mutant to colonisation but inoculation does change competitive interactions with wildtype tomato. New Phytol 161:485-494

Dehne H-W, Schönbeck F (1979) Untersuchungen zum Einfluß der endotrophen Mycorrhiza auf Pflanzenkrankheiten. Phytopathol Z 95:105-110

Hao W, Ren LX, Ran W, Shen QR (2010) Allelopathic effects of root exudates from watermelon and rice plants on Fusarium oxysporum f.sp. niveum. Plant Soil 336:485-497

Kubota M, Hyakumachi M (2004) Morphology and colonization peference of arbuscular mycorrhizal fungi in Clethra barbinervis,
Cucumis sativus, and Lycopersium esculentum. Mycoscience 45:206-213

McGonigle T, Miller M, Evans D, Fairchild G, Swan J (1990) A new method which gives an objective measure of colonization of roots by vesicular-arbuscular mycorrhizal fungi. New Phytol 115:495501

Nelson P, Toussoun T, Marasas W (1983) Fusarium species. An illustrated manual for identification. State University Press, University Park, Penn

Newsham KK, Fitter AH, Watkinson AR (1995) Multi-functionality and biodiversity in arbuscular mycorrhizas. Trends Ecol Evol 10:407-411

Ratnadass A, Fernandes P, Avelino J, Habib R (2012) Plant species diversity for sustainable management of crop pests and diseases in agroecosystems: a review. Agron Sustain Dev 32:273-303

Schroeder-Moreno MS, Janos DP (2008) Intra- and inter-specific density affects plant growth responses to arbuscular mycorrhizas. Botany 86:1180-1193

Sikes BA, Cottenie K, Klironomos JN (2009) Plant and fungal identity determines pathogen protection of plant roots by arbuscular mycorrhizas. J Ecol 97:1274-1280

Singh R, Adholeya A, Mukerji KG (2000) Mycorrhiza in control of soil borne pathogens. In: Mukerji KG, Chamola BP, Snigh J (eds) Mycorrhizal biology. Kluwer Academic/Plenum, New York, pp 173-196

Smith SE, Read DJ (2008) Mycorrhizal symbiosis, 3rd edn. Acadamic, London

St-Arnaud M, Vujanovic V (2007) Effect of the arbuscular mycorrhizal symbiosis on plant diseases and pests. In: Hamel C, Plenchette C (eds) Mycorrhizae in crop production. Haworth, Binghamton, pp $67-122$

Steinkellner S, Mammerler R, Vierheilig H (2005) Microconidia germination of the tomato pathogen Fusarium oxysporum in the presence of root exudates. J Plant Interact 1:23-30

Steinkellner S, Hage-Ahmed K, García-Garrido JM, Illana A, Ocampo JA, Vierheilig H (2011) A comparison of wild-type, old and modern tomato cultivars in the interaction with the arbuscular mycorrhizal fungus Glomus mosseae and the tomato pathogen Fusarium oxysporum f. sp. lycopersici. Mycorrhiza 22:189-194

van der Heijden M, Wiemken A, Sanders I (2003) Different arbuscular mycorrhizal fungi alter coexistence and resource distribution between co-occuring plant. New Phytol 157:569-578

Vierheilig H, Coughlan AP, Wyss U, Piché Y (1998) Ink and vinegar, a simple staining technique for arbuscular-mycorrhizal fungi. Appl Environ Microbiol 64:5004-5007

Whipps JM (2004) Prospects and limitations for mycorrhizas in biocontrol of root pathogens. Can J Bot 82:1198-1227

Xavier L, Boyetchko S (2004) Arbuscular mycorrhizal fungi in plant disease control. In: Arora D, Bridge P, Bhatnagar D (eds) Fungal biotechnology in agricultural, food, and environmental applications. Marcel Dekker, Inc., New York

Yu JQ (1999) Allelopathic suppression of Pseudomonas solanacearum infection of tomato (Lycopersicon esculentum) in a tomatochinese chive (Allium tuberosum) intercropping system. J Chem Ecol 25:2409-2417 